\title{
Wogonin protects human retinal pigment epithelium cells from LPS-induced barrier dysfunction and inflammatory responses by regulating the TLR4/NF-kB signaling pathway
}

\author{
$\mathrm{CHEN} \mathrm{CHEN}^{1}$, DANNI GUO ${ }^{2}$ and GUOHUA LU ${ }^{1}$ \\ ${ }^{1}$ Eye Institute, Changzhou No. 2 People's Hospital of Nanjing Medical University, Changzhou, Jiangsu 213003; \\ ${ }^{2}$ Department of Otorhinolaryngology Head \& Neck Surgery, Hospital of Jiangnan University, Wuxi, Jiangsu 214062, P.R. China
}

Received October 21, 2015; Accepted November 18, 2016

DOI: $10.3892 / \mathrm{mmr} .2017 .6252$

\begin{abstract}
Inflammation in the retinal pigment epithelium is an important contributor to the pathogenesis of age-related macular degeneration. Wogonin is a flavonoid isolated from the root of Scutellaria baicalensis and has multiple pharmacological effects, including anti-inflammatory effects. The present study sought to determine if the pharmacological effects of wogonin were relevant to the treatment of AMD. ARPE-19 cells were pre-conditioned with different concentrations of wogonin $(0-50 \mu \mathrm{M})$ prior to induction of inflammation with LPS $(2 \mu \mathrm{g} / \mathrm{ml})$. Transepithelial electrical resistance analysis demonstrated that $24 \mathrm{~h}$ treatment with 10 and $50 \mu \mathrm{M}$ wogonin ameliorated LPS-induced changes. Reverse transcription-quantitative polymerase chain reaction (RT-qPCR) and immunofluorescence analyses revealed that wogonin restrained LPS-induced tight junction proteins, claudin-1 and ZO-1. LPS-induced upregulation of inflammatory mediators in ARPE-19 cells, including IL-1 $\beta$, IL-6, IL-8, cyclooxygenase-2 (COX-2), inducible nitric oxide synthase (iNOS) and TNF- $\alpha$ was reduced after pre-treatment with wogonin. In addition, RT-qPCR and western blotting demonstrated that wogonin inhibited the expression of TLR4 in LPS-stimulated ARPE-19 cells. This is a novel mechanism indicating that pre-treatment with wogonin could attenuate the TLR4/NF- $\mathrm{B}$-mediated inflammatory response in LPS-stimulated ARPE-19 cells, and thus could be a potential therapy for the treatment of AMD.
\end{abstract}

Correspondence to: Dr Guohua Lu, Eye Institute, Changzhou No. 2 People's Hospital of Nanjing Medical University, 29 Xinglong Lane, Changzhou, Jiangsu 213003, P.R. China

E-mail: luguohuacz@163.com

Key words: inflammation, age-related macular degeneration, retinal pigment epithelium, ARPE-19, wogonin, toll-like receptor 4, $\mathrm{NF}-\kappa \mathrm{B}$

\section{Introduction}

Age-related macular degeneration (AMD) is the leading cause of irreversible sight loss in the elderly, with risk factors including aging, genetic characteristics, smoking, obesity and hypertension $(1,2)$. The two clinical classifications of AMD are dry (nonneovascular) and wet (neovascular) AMD (3-5). Dry AMD affects the majority of patients with AMD, and a small number of dry AMD cases progress to become wet AMD by abnormal growth of blood vessels from the choroid into the macula. A major pathological hallmark of dry AMD is the presence of age-dependent degenerative damage to the retinal pigment epithelium (RPE), a monolayer of hexagonal epithelial cells located adjacent to, and physically interacting with, retinal photoreceptors, forming the outer blood-retinal barrier (BRB) (6). RPE is a common barrier for solutes and fluids from the choroidal vasculature that must access the inner retina $(7,8)$. Strict control of fluids and solutes across the BRB is achieved by well-developed tight junctions, which mean that the liquid is not able to penetrate the barrier between the two cells. Zonula occludens-1 and claudin-1 are the most-studied tight junction proteins, with most attention focusing on their relation to the $\operatorname{BRB}(9,10)$.

RPE cells are important in retinal physiology and pathology (9). Previous studies have revealed that abnormal distribution or expression of tight junction proteins in RPE cells are involved in AMD pathogenesis (10). Increased BRB permeability allows toxic substances and microorganisms to cross the choroidal vasculature, resulting in the activation of Toll-like receptor 4 (TLR4) (9). TLRs are a family of signal transduction molecule, which are transmembrane proteins usually expressed by sentinel cells and recognize structurally conserved molecules from micro organisms. TLR4-mediated signaling pathways have been revealed to activate nuclear transcription factor $-\kappa \mathrm{B}(\mathrm{NF}-\kappa \mathrm{B})$, suggesting that TLR-4 is critical to the regulation of multiple proinflammatory genes, including cytokines, chemokines, cyclooxygenase-2 (COX-2), interleukin (IL)-6, IL-8 and inducible nitric oxide synthase (iNOS) (11). Therefore, the activation of NF- $\kappa \mathrm{B}$ has been proposed as a cause of ocular inflammatory disease. AMD is a multifactorial disease that has several risk factors, including aging, genetic characteristics and smoking. The involvement 
of oxidative stress and inflammatory changes have been highlighted in multiple studies (4). Therefore, inhibiting inflammation and improving BRB function is the focus of pathophysiology research regarding AMD.

5,7-dihydroxy-8-methoxyflavone, or wogonin, is a naturally-derived ingredient isolated from the roots of Scutellaria baicalensis Georgi, commonly known as Huang-Qin. In traditional Chinese medicine, this substance has been used to treat allergies, inflammatory diseases and tumors (11-13). Previous studies have demonstrated that wogonin suppresses LPS-induced expression of iNOS, tumor necrosis factor- $\alpha$ (TNF- $\alpha), N O$, and IL-1 $\beta$ in microglia via inhibition of $\mathrm{NF}-\kappa \mathrm{B}$ activation $(14,15)$. It has also been revealed that wogonin $\left(10^{-6}-10^{-5} \mathrm{M}\right)$ inhibits IL- 6 and IL- 8 gene expression and down-regulates the inflammation-associated protein COX-2 through suppression of $\mathrm{NF}-\kappa \mathrm{B}$ binding in a murine skin inflammation model $(16,17)$. This evidence demonstrates the benefit of wogonin treatment in inflammatory diseases, but little is known about the function of wogonin in relation to AMD.

The human RPE cell line ARPE-19 has been demonstrated to show structural and functional properties that are characteristic to RPE cells in vivo, and so is ideal to use for in vitro studies (18). The present study investigated both the anti-inflammatory function of wogonin in LPS-induced ARPE-19 cells, and the molecular mechanisms through which it modulates inflammation.

\section{Materials and methods}

Cell culture and treatments. ARPE-19 cells (American Type Culture Collection, Manassas, VA, USA) were seeded in Dulbecco's modified Eagle's medium/F-12, a human amniotic membrane nutrient mixture (Thermo Fisher Scientific, Inc., Waltham, MA, USA) with $10 \%$ fetal bovine serum (FBS; Thermo Fisher Scientific, Inc.). Cultures were grown in a humidified incubator at $37^{\circ} \mathrm{C}$ in an atmosphere of $5 \% \mathrm{CO}_{2}$. Culture medium was changed every 2 days. An additional $2 \mu \mathrm{g} / \mathrm{ml}$ lipopolysaccharide (LPS; Sigma-Aldrich; Merck Millipore, Darmstadt, Germany) was added to the medium for the LPS groups for $24 \mathrm{~h}$, as previously described (19). ARPE-19 cells $\left(5 \times 10^{4}\right.$ cells/well) were cultured in 96 -well plates for $24 \mathrm{~h}$ at $37^{\circ} \mathrm{C}$, then pre-treated with different concentrations of wogonin $(0-50 \mu \mathrm{M})$ for $24 \mathrm{~h}$, followed by $24 \mathrm{~h}$ LPS stimulation. The concentrations of wogonin used to treat ARPE-19 cells were based on the results of previous studies (19-21).

Measurement of transepithelial electrical resistance (TEER). TEER was used to measure the paracellular permeability of cell monolayers. ARPE-19 cells $\left(5 \times 10^{4}\right.$ cells/well $)$ were cultured on microporous filter membranes $(0.4 \mu \mathrm{m}$ pore size and $6.5 \mathrm{~mm}$ diameter; Corning Incorporated, Corning, NY, USA) of apical chambers until the confluent monolayer achieved a TEER $>300 \Omega \mathrm{cm}^{2}$ ( 15-18 days), indicating a tight monolayer. A voltmeter (Millicell-ERS; Merck Millipore) was used to measure TEER as previously described (22): TEER $\left(\Omega \mathrm{cm}^{2}\right)=[$ total resistance-blank resistance $(\Omega)] \times\left[\operatorname{area}\left(\mathrm{cm}^{2}\right)\right]$. Measurements were repeated at least three times for each well and each experiment was repeated for at least five different wells.
RNA isolation and reverse transcription-quantitative polymerase chain reaction ( $R T-q P C R)$. Following $24 \mathrm{~h}$ of LPS exposure, RT-qPCR was performed to detect the mRNA expression levels of tight junction components $\mathrm{ZO}-1$ and claudin-1 in ARPE-19 cells. mRNA expression levels of biological markers of inflammation, COX-2, iNOS and TNF- $\alpha$, were also determined. Total RNA was isolated from ARPE-19 cells using TRIzol (Thermo Fisher Scientific, Inc.) according to the manufacturer's protocol. First-strand cDNA was synthesized using the PrimeScript RT kid (cat. no. DRR0375, Takara Bio Inc., Otsu, Japan). qPCR was performed using an ABI Prism 7500 Sequence Detection System (Applied Biosystems; Thermo Fisher Scientific, Inc.) with thermocycling conditions as follows: An initial denaturation step at $95^{\circ} \mathrm{C}$ for $5 \mathrm{~min}$, followed by 40 cycles of denaturation at $95^{\circ} \mathrm{C}$ for $15 \mathrm{sec}$, annealing at $60^{\circ} \mathrm{C}$ for $60 \mathrm{sec}$ and extension at $72^{\circ} \mathrm{C}$ for $30 \mathrm{sec}$. The expression of each PCR product was analyzed using the $2^{-\Delta \Delta \mathrm{Cq}}$ method relative to $\beta$-actin (23). The SYBR Green real-time PCR master mixes (cat. no. PA-012 and cat. no. PA-011) were from SuperArray Bioscience Corporation (Frederick, MD, USA). The primers of the target genes were as follows: ZO-1, forward 5'-AGC CTGCAAAGCCAGCTCA-3' and reverse 5'-AGTGGCCTG GATGGGTTCATAG-3'; claudin-1, forward 5'-GCATGA AGTGTATGAAGTGCTTGGA-3' and reverse 5'-CGATTC TATTGCCATACCATGCTG-3'; TLR4, forward 5'-GAG CCGTTGGTGATCTTTG-3' and reverse 5'-TGCCGTTTC TTGTTCTTCC-3'; $\beta$-actin, forward 5'-GGCGGACTATGA CTTAGTTG-3' and reverse 5'-AAACAACAATGTGCAATC AA-3'; iNOS, forward 5'-AGAGAGATCGGGTTCACA-3' and reverse 5'-CACAGAACTGAGGGTACA-3'; COX-2, forward 5'-TTAAAATGAGATTGTCCGAA-3' and reverse 5'-AGA TCACCTCTGCCTGAGTA-3'.

Immunofluorescence. Immunostaining of ARPE-19 cells were performed as described (24). ARPE-19 cells were fixed with $4 \%$ PFA for $1 \mathrm{~h}$, washed with PBS containing $0.1 \%$ Triton $\mathrm{X}-100$ (PBST), and blocked at $37^{\circ} \mathrm{C}$ for $30 \mathrm{~min}$ in PBST supplemented with $10 \%$ FBS (Thermo Fisher Scientific, Inc.). ARPE-19 cells were incubated overnight at $4^{\circ} \mathrm{C}$ with ZO-1 antibody (cat. no. 8193; dilution, 1:100, Cell Signaling Technology, Inc., Danvers, MA, USA) or claudin-1 antibody (cat. no. 4933; dilution, 1:100, Cell Signaling Technology, Inc.), then incubated with fluorescein isothiocyanate-conjugated goat anti-mouse immunoglobulin $\mathrm{G}$ secondary antibody (cat. no. sc-2357; dilution, 1:5,000, Santa Cruz Biotechnology, Inc.) at $37^{\circ} \mathrm{C}$ for $2 \mathrm{~h}$. This was followed by DNA staining using 4',6-diamidino-2-phenylindole. Fluorescent signals were visualized with the Leica TCS SP2 Confocal Spectral Microscope (Leica Microsystems, Inc., Buffalo Grove, IL, USA).

Enzyme-linked immunosorbent assay (ELISA). ARPE-19 cells were plated in 24-well culture plates at a density of $5 \times 10^{4}$ cells per well and treated as they were to measure the TEER. ARPE-19 cells were collected and centrifuged at 1,500 x $g$ at $4^{\circ} \mathrm{C}$ for $5 \mathrm{~min}$ following $24 \mathrm{~h}$ LPS treatment in the presence or absence of wogonin. ELISA was performed to measure IL-1 $\beta$ (cat. no. 432601), IL-6 (cat. no. 430506) and IL-8 (cat. no. 431506) according to the manufacturer's instructions (BioLegend ELISA MAX ${ }^{\mathrm{TM}}$ Deluxe kit; BioLegend, Inc., San 

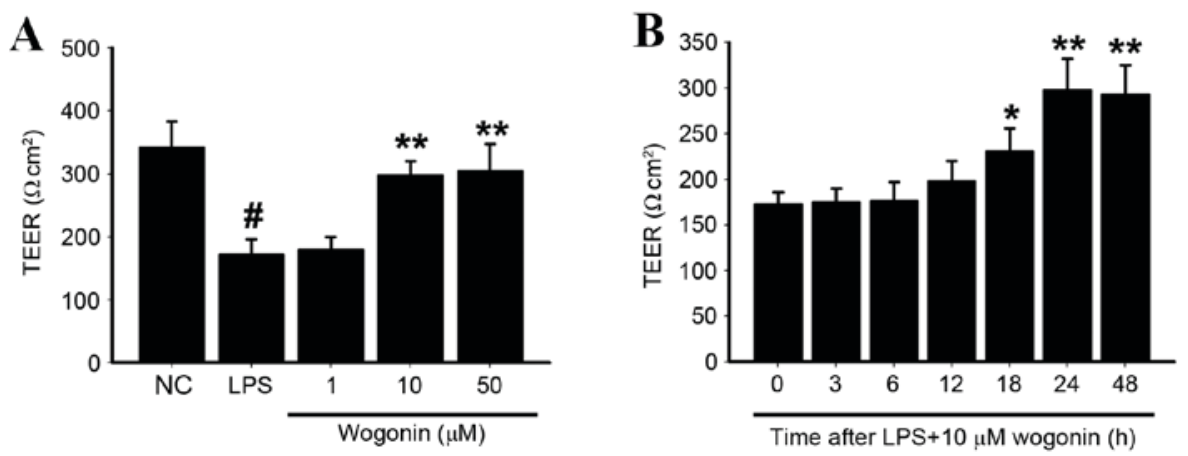

Figure 1. Effect of wogonin on TEER in LPS-stimulated ARPE-19 cells (A) TEER in LPS-stimulated ARPE-19 cells, incubated with 1, 10 and $50 \mu \mathrm{M}$ wogonin for $24 \mathrm{~h}$. (B) TEER in LPS-stimulated ARPE-19 cells treated with wogonin for different durations. Values are presented as the mean + standard deviation $(\mathrm{n}=3){ }^{*} \mathrm{P}<0.001$ vs. NC group; ${ }^{*} \mathrm{P}<0.05$ and ${ }^{* *} \mathrm{P}<0.001$ vs. LPS group. TEER, transendothelial electrical resistance; LPS, lipopolysaccharide; NC, unstimulated negative control cells.

Diego, CA, USA). ELISA was performed in triplicate in three independent experiments.

Western blot. Total protein was extracted from ARPE-19 cells that had been lysed with a buffer (1 M Tris-HCl $\mathrm{pH} 7.5$, $1 \%$ Triton X-100, 10\% sodium dodecyl sulfate [SDS], $0.5 \%$ sodium deoxycholate, $0.5 \mathrm{M}$ EDTA, $10 \mu \mathrm{g} / \mathrm{ml}$ leupeptin, $10 \mu \mathrm{g} / \mathrm{ml}$ aprotinin, and $1 \mathrm{mM}$ phenylmethanesulfonyl fluoride or phenylmethylsulfonyl fluoride [PMSF]) at $4^{\circ} \mathrm{C}$ for $2 \mathrm{~h}$. The soluble proteins were separated by $10 \%$ SDS-polyacrylamide gel electrophoresis and transferred to polyvinylidene difluoride filter membranes (Merck Millipore). Primary antibodies were incubated overnight at $4^{\circ} \mathrm{C}$, including inhibitor of $\mathrm{NF}-\kappa \mathrm{B}(\mathrm{I} \kappa \mathrm{B}$; cat. no. 9242; dilution, 1:500; Cell Signaling Technology, Inc.), phospho-IкB (cat. no. 9246; dilution, 1:500; Cell Signaling Technology, Inc.), TLR4 (cat. no. sc-M300; dilution, 1:500, Santa Cruz Biotechnology, Inc.) or $\beta$-actin antibody (cat. no. sc-1616; dilution, 1:500, Santa Cruz Biotechnology, Inc., Dallas, TX, USA). Horseradish peroxidase-labelled secondary antibody (cat. no. sc-3901; dilution, 1:10,000, Santa Cruz Biotechnology, Inc.) was added at $37^{\circ} \mathrm{C}$ for $1 \mathrm{~h}$. Following this the membranes were washed extensively in Tris-buffered saline+Tween-20 (25 mmol/l Tris, $\mathrm{pH} 7.5,150 \mathrm{mmol} / \mathrm{l} \mathrm{NaCl}$ and $0.1 \%$ Tween-20) for $1 \mathrm{~h}$. The films were visualized using femto LUCENT ${ }^{\circledR}$ (Geno Technology Inc., Saint Louis, MO, USA). All experiments were repeated independently four times in triplicate.

Statistical analysis. Statistical analysis was performed using GraphPad Prism software (version 5.0; GraphPad Software, Inc., La Jolla, CA, USA). All values were expressed as the mean \pm standard deviation. Data was analyzed with one-way ANOVA tests followed by Tukey's range tests. $\mathrm{P}<0.05$ was considered to indicate a statistically significant difference.

\section{Results}

The effect of wogonin on TEER changes in LPS-stimulated ARPE-19 cells. TEER was significantly reduced in cells stimulated with LPS compared with the unstimulated negative control (NC) cells $(\mathrm{P}<0.05$; Fig. 1A). The effect of different concentrations of wogonin on LPS-stimulated ARPE-19 cells was then investigated. Significant increases in TEER were observed in cells treated with 10 and $50 \mu \mathrm{M}$ wogonin compared with the LPS-only group $(\mathrm{P}<0.05$ and $\mathrm{P}<0.05$ respectively; Fig. 1A). Treatment with $10 \mu \mathrm{M}$ wogonin following LPS-stimulation resulted in increasing TEER as time increased, peaking at $24 \mathrm{~h}(\mathrm{P}<0.05$ at 18, 24 and $48 \mathrm{~h}$; Fig. 1B).

The effect of wogonin on the expression of ZO-1 and claudin-1 in LPS-stimulated ARPE-19 cells. ZO-1 and claudin-1 mRNA expression levels were significantly increased in ARPE-19 cells stimulated with LPS compared with $\mathrm{NC}(\mathrm{P}<0.05$ and $\mathrm{P}<0.05$, respectively; Fig. $2 \mathrm{~A}$ and $\mathrm{B}$, respectively). Treatment with 10 and $50 \mu \mathrm{M}$ wogonin for $24 \mathrm{~h}$ resulted in significantly reduced ZO-1 and claudin-1 expression in LPS-stimulated ARPE-19 cells compared with LPS stimulated/wogonin untreated cells $(\mathrm{P}<0.05$; Fig. 2A and $\mathrm{B})$. The changes observed in immunofluorescence staining demonstrated similar trends to those observed in RT-qPCR analysis: The groups treated with wogonin following LPS stimulation exhibited higher ZO-1 and claudin-1 expression than the group treated with LPS alone (Fig. 2C). These results indicated the protective effects of wogonin against inflammation in the LPS-induced ARPE-19 cells.

Key inflammatory mediators in LPS-stimulated ARPE-19 cells are inhibited by wogonin. Expression levels of COX-2, iNOS and TNF- $\alpha$ mRNA were significantly increased in the LPS-stimulated cells compared with $\mathrm{NC}(\mathrm{P}<0.05, \mathrm{P}<0.05$ and $\mathrm{P}<0.05$; Fig. 3A-C). COX-2, iNOS and TNF- $\alpha$ mRNA expression levels in LPS-stimulated cells were slightly decreased with $1 \mu \mathrm{M}$ wogonin treatment compared with the group stimulated with LPS alone, and significantly decreased by $10 \mu \mathrm{M}$ and $50 \mu \mathrm{M}$ wogonin treatments $(\mathrm{P}<0.05$; Fig. $3 \mathrm{~A}-\mathrm{C})$. The ELISA results indicated that protein expression levels of IL-1 $\beta$, IL-6 and IL- 8 were also significantly increased in LPS-stimulated ARPE-19 cells compared with NC, and significantly reduced in LPS-stimulated cells treated with 10 and $50 \mu \mathrm{M}$ wogonin compared with LPS-stimulated/wogonin-untreated cells $(\mathrm{P}<0.05$; Fig. 3D-F). This suggests that wogonin suppresses inflammatory activity in LPS-stimulated ARPE-19 cells.

Effect of wogonin on NF- $\kappa B$ activation in LPS-stimulated ARPE-19 cells. NF- $\kappa \mathrm{B}$ is central to the regulation of several 

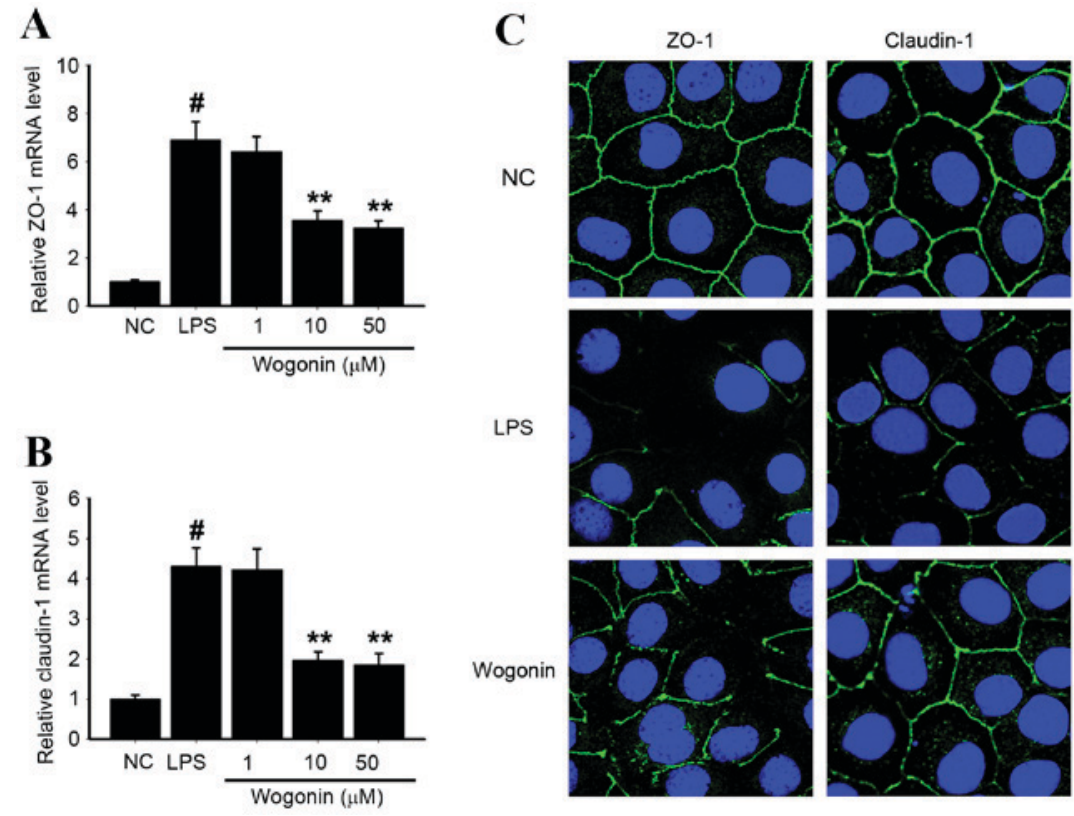

Wogonin
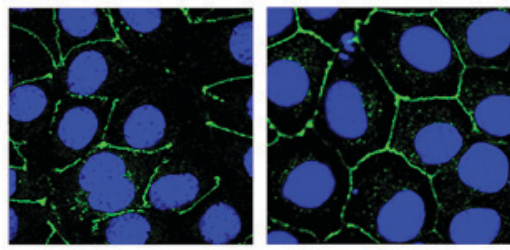

Figure 2. Effects of wogonin on expression of ZO-1 and claudin-1 in LPS-stimulated ARPE-19 cells. (A) RT-qPCR analysis of ZO-1 mRNA expression levels, relative to $\beta$-actin. (B) RT-qPCR analysis of claudin-1 expression levels, relative to $\beta$-actin. Values are presented as the mean + standard deviation $(\mathrm{n}=3){ }^{\#} \mathrm{P}<0.001$ vs. $\mathrm{NC}$ group; ${ }^{* *} \mathrm{P}<0.001$ vs. LPS group. (C) Immunofluorescent staining of ZO-1 and claudin-1. The nuclear phenotype was investigated by 4',6-diamidino-2-phenylindole staining. Scale bar=25 $\mu \mathrm{m}$. ZO-1, zonula occludens-1/tight junction protein-1; LPS, lipopolysaccharide; RT-qPCR, reverse transcription-quantitative polymerase chain reaction; $\mathrm{NC}$, unstimulated negative control cells.

A

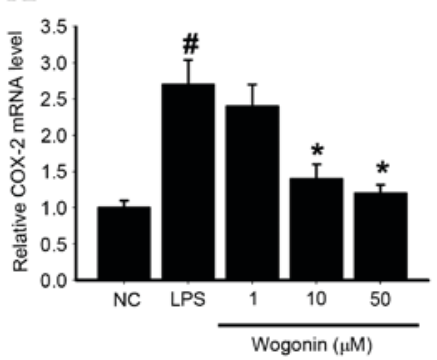

B
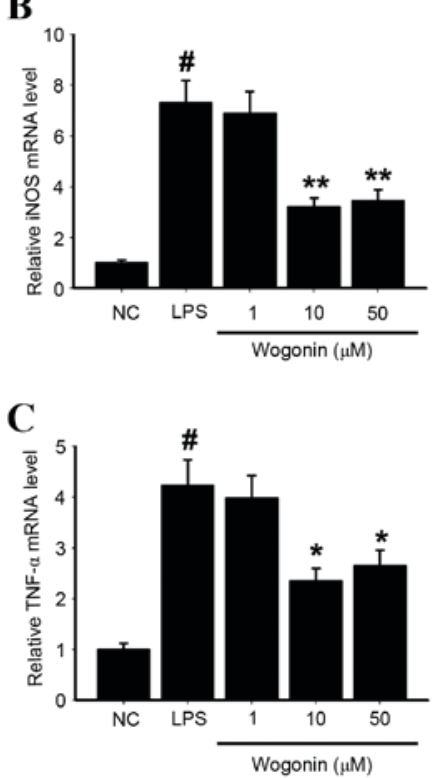

D

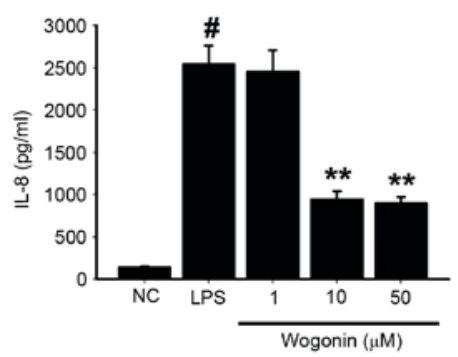

$\mathbf{E}$

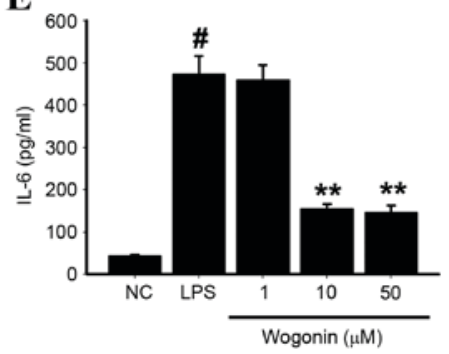

F

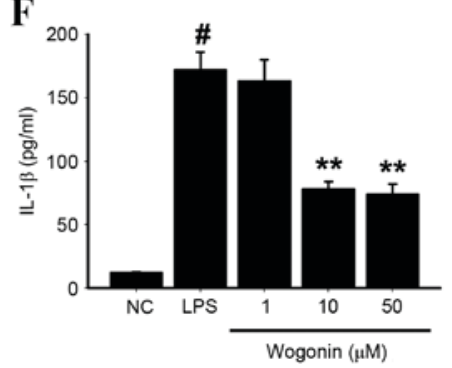

Figure 3. Effect of wogonin on the expression of inflammatory mediators in LPS-stimulated ARPE-19 cells. Reverse transcription-quantitative polymerase chain reaction analysis of mRNA expression levels of (A) COX-2, (B) iNOS and (C) TNF- $\alpha$ in ARPE-19 cells. Enzyme-linked immunosorbent assay analysis of protein expression levels of (D) IL-8, (E) IL-6 and (F) IL-1 $\beta$ in ARPE-19 cells. Values are presented as the mean + standard deviation ( $\mathrm{n}=3$ ). ${ }^{*} \mathrm{P}<0.001 \mathrm{vs}$. NC group; " $\mathrm{P}<0.05$ and ${ }^{* *} \mathrm{P}<0.001$ vs. LPS group. LPS, lipopolysaccharide; COX-2, cyclooxygenase-2; iNOS, inducible nitric oxide synthase; TNF- $\alpha$, tumor necrosis factor- $\alpha$; IL, interleukin; NC, unstimulated negative control cells. 
A

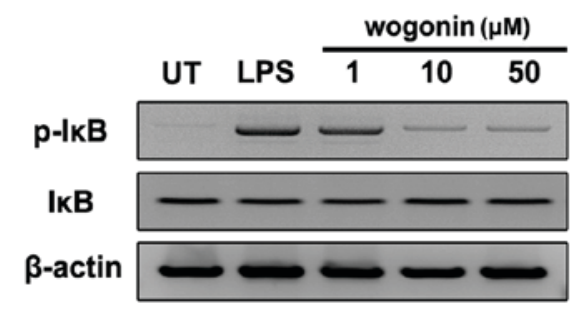

B

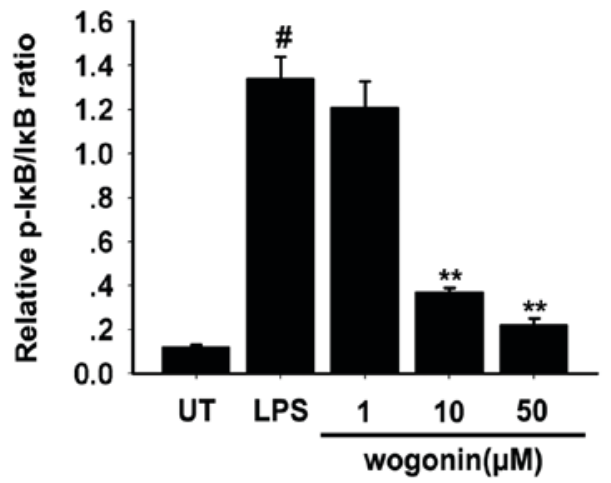

Figure 4. Effect of wogonin on NF- $\kappa \mathrm{B}$ activation in LPS-stimulated

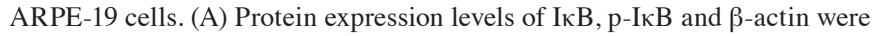
analysed by western blot analysis. Densitometric analysis of (B) $p-\mathrm{I} \kappa \mathrm{B} / \mathrm{I} \kappa \mathrm{B}$ ratio, with quantification relative to the $\beta$-actin control. Values are presented as the mean \pm standard deviation $(\mathrm{n}=3) .{ }^{\#} \mathrm{P}<0.001$ and ${ }^{\# \#} \mathrm{P}<0.05$ vs. NC group; ${ }^{*} \mathrm{P}<0.05$ and ${ }^{* *} \mathrm{P}<0.001$ vs. LPS group. NFkB, nuclear transcription factor $\kappa \mathrm{B}$;

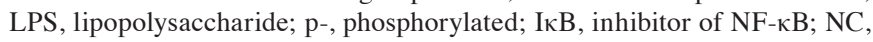
unstimulated negative control cells.

genes involved in the inflammatory response (24). Activation of NF- $\kappa \mathrm{B}$ by LPS is induced by a cascade of events leading to the activation of $\mathrm{I} \kappa \mathrm{B}$. The rate of tyrosine phosphorylation of p65 and degradation of $\mathrm{I} \kappa \mathrm{B}$ could measure the effects of wogonin on LPS-induced NF- $\kappa \mathrm{B}$ activation. LPS stimulation was observed to significantly increase the serine phosphorylation of IкB (Fig. 4). Treatment of LPS-stimulated ARPE-19 cells with 10 and $50 \mu \mathrm{M}$ wogonin significantly decreased I $\kappa \mathrm{B}$ activation in response to LPS compared with the cells stimulated with LPS alone ( $\mathrm{P}<0.05$; Fig. 4). Wogonin may, therefore, significantly inhibit LPS-induced $N F-\kappa B$ transcriptional activity in ARPE-19 cells.

Effect of wogonin on TLR4 expression in LPS-induced ARPE-19 cells. As activation of TLR4 stimulates the activation of $\mathrm{NF}-\kappa \mathrm{B}$, the effects of wogonin on TLR4 expression were examined. Western blotting revealed that basal TLR4 expression was low in the NC group (Fig. 5A). The protein expression levels of TLR4 were significantly increased in LPS-stimulated ARPE-19 cells compared with NC cells ( $\mathrm{P}<0.05$; Fig. 5A). However, treatment of LPS-stimulated cells with 10 and $50 \mu \mathrm{M}$ wogonin resulted in significantly lower TLR4 protein expression levels than LPS-stimulated cells $(\mathrm{P}<0.05$ and $\mathrm{P}<0.05$, respectively; Fig. 5A). RT-qPCR analyses of mRNA expression levels were consistent with the protein results (Fig. 5B). This suggests that wogonin has a significant inhibitory effect on LPS-stimulated TLR4 expression in ARPE-19
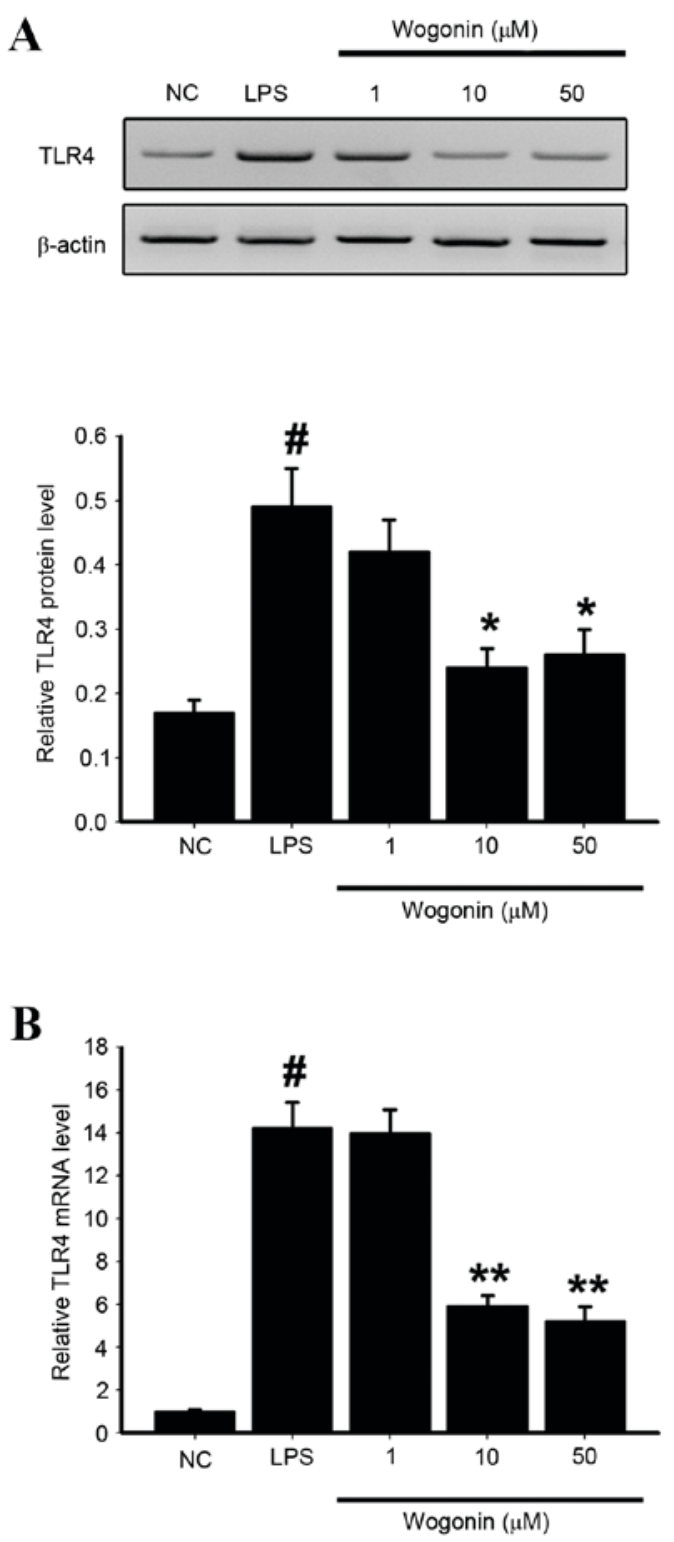

Figure 5. Effect of wogonin on mRNA and protein expression levels of TLR4 in LPS-stimulated ARPE-19 cells. (A) Western blot analysis of TLR4 protein expression levels, with quantification relative to $\beta$-actin. (B) Reverse transcription-quantitative polymerase chain reaction analysis of mRNA expression levels of TLR4 relative to $\beta$-actin. Values are presented as the mean + standard deviation $(\mathrm{n}=3)$. ${ }^{\#} \mathrm{P}<0.001$ vs. NC group; ${ }^{*} \mathrm{P}<0.05$ and ${ }^{* *} \mathrm{P}<0.001$ vs. LPS group. TLR4, toll-like receptor 4; LPS, lipopolysaccharide; $\mathrm{NC}$, unstimulated negative control cells.

cells. Therefore, wogonin may inhibit the activation of inflammation-associated cytokines through the TLR4/NF- $\kappa \mathrm{B}$ pathway, which may be the molecular mechanism underlying the protective effect of wogonin on RPE cells.

\section{Discussion}

The present study presents three novel findings. First, wogonin inhibits inflammation in LPS-stimulated ARPE-19 cells, which results in the protection of the tight junction proteins ZO-1 and claudin-1. By protecting endothelial tight junctions, wogonin treatment helps maintain an intact BRB. Secondly, wogonin attenuated the LPS-induced inflammatory response via the 
inhibition of IL-1 $\beta$, IL-6, IL-8, COX-2, iNOS and TNF- $\alpha$ gene expression. This is consistent with the findings of previous studies, that demonstrated the ability of wogonin to inhibit IL-1 $\beta$-induced IL- 6 and IL-8 expression via the suppression of NF- $\mathrm{kB}$ binding activities (19). Thirdly, wogonin inhibited the activation of the TLR4/NF-kB pathway, which is also associated with the inflammatory response. Previous studies have demonstrated that wogonin acts as a potent inhibitor of several other kinases involved in signal transduction (23). This is consistent with the findings of the present study, with wogonin revealed to attenuate AMD.

Lipopolysaccharide (LPS), also known as endotoxin, is the major cell wall constituent of gram-negative bacteria, and functions as a microglia activator via induction of TLR4 (25). In vitro assays have demonstrated that LPS induces inflammation in RPE, followed by subsequent destruction of the outer BRB $(25,26)$. Therefore, cultured ARPE-19 cells were exposed to LPS to induce inflammation. Inflammation depends largely on gene expression and shares key regulators, including COX-2, iNOS and TNF- $\alpha$ (24). TLR4-mediated $\mathrm{NF}-\kappa \mathrm{B}$ signaling is thought to be central to the regulation of numerous inflammatory responses, and considered to be one of the indicators for ocular inflammatory disease (24). Activation of the NF- $\mathrm{kB}$ transcription pathway is considered to be essential for expression of pro-inflammatory genes encoding enzymes such as COX-2, iNOS and TNF- $\alpha$ (27). It has previously been demonstrated that suppression of TLR4/NF-kB signaling by anti-inflammatory agents reduces RPE cell damage (23). The present study also observed that TLR4/NF-kB signaling pathway activation in AMD was attenuated by wogonin treatment. The obtained data were in agreement with previous studies demonstrating that wogonin suppresses neutrophil infiltration and reduces injury-induced IL-1 $\beta$, IL-6, IL-8 and COX-2 expression, thereby ameliorating RPE damage (24).

The most abundant activated form of NF- $\mathrm{BB}$ is a heterodimer of p50 and p65, çontaining transcriptional activation domains necessary for gene induction (28). In resting cells, the NF- $\mathrm{kB}$ heterodimer is held in the cytosol through interaction with IкB inhibitory proteins. Following exposure to pro-inflammatory stimuli IкB becomes phosphorylated, ubiquitinated, and then degraded $(28,29)$. The present study provides further support for targeting this mechanism of NF-kB activation to provide protection from inflammation. Wogonin reduced the stimulation effect of LPS on the phosphorylation of IкB and the expression of iNOS, COX-2 and TNF- $\alpha$ together. This suggests that NF-kB was activated via phosphorylation of IкB.

In conclusion, these findings indicate that the upstream factors (TLR4/NF-kB) and downstream factors (COX-2, iNOS, TNF- $\alpha$ activity and IL-1 $\beta$, IL-6, IL-8 expression) of the TLR4/NF-kB pathway were associated with the neuroprotective effects of RPE cells and may be involved in the pathogenesis of AMD. Further studies are required to explore the potential efficacy of wogonin in other ocular diseases against inflammatory responses.

\section{References}

1. Lu L, Hackett SF, Mincey A, Lai H and Campochiaro PA Effects of different types of oxidative stress in RPE cells. J Cell Physiol 206: 119-125, 2006.
2. Ding X, Patel $M$ and Chan CC: Molecular pathology of age-related macular degeneration. Prog Retin Eye Res 28: 1-18, 2009.

3. Anderson DH, Mullins RF, Hageman GS and Johnson LV: A role for local inflammation in the formation of drusen in the aging eye. Am J Ophthalmol 134: 411-431, 2002.

4. Salminen A, Kauppinen A, Hyttinen JM, Toropainen E and Kaarniranta K: Endoplasmic reticulum stress in age-related macular degeneration: Trigger for neovascularization. Mol Med 16: 535-542, 2010.

5. Nowak JZ: Age-related macular degeneration (AMD): Pathogenesis and therapy. Pharmacol Rep 58: 353-363, 2006.

6. Chen C, Cano M, Wang JJ, Li J, Huang C, Yu Q, Herbert TP, Handa JT and Zhang SX: Role of unfolded protein response dysregulation in oxidative injury of retinal pigment epithelial cells. Antioxid Redox Signal 20: 2091-2106, 2014.

7. Kucuksayan E, Konuk EK, Demir N, Mutus B and Aslan M: Neutral sphingomyelinase inhibition decreases ER stress-mediated apoptosis and inducible nitric oxide synthase in retinal pigment epithelial cells. Free Radic Biol Med 72: 113-123, 2014.

8. Strauss O: The retinal pigment epithelium in visual function. Physiol Rev 85: 845-881, 2005.

9. Yoshikawa T, Ogata N, Izuta H, Shimazawa M, Hara H and Takahashi K: Increased expression of tight junctions in ARPE-19 cells under endoplasmic reticulum stress. Curr Eye Res 36: 1153-1163, 2011.

10. Du M, Wu M, Fu D, Chen J, Wilson K and Lyons TJ: Effects of modified LDL and HDL on retinal pigment epithelial cells: A role in diabetic retinopathy? Diabetologia 56: 2318-2328, 2013.

11. Yeh CH, Yang ML, Lee CY, Li YC, Chen CJ and Kuan YH: Wogonin attenuates endotoxin-induced prostaglandin E2 and nitric oxide production via Src-ERK1/2-NFKB pathway in BV-2 microglial cells. Environ Toxicol 29: 1162-1170, 2014.

12. Gibbons HM and Dragunow M: Microglia induce neural cell death via a proximity-dependent mechanism involving nitric oxide. Brain Res 1084: 1-15, 2006.

13. Lu H, Gao F, Shu G, Xia G, Shao Z, Lu H and Cheng K: Wogonin inhibits the proliferation of myelodysplastic syndrome cells through the induction of cell cycle arrest and apoptosis. Mol Med Rep 12: 7285-7292, 2015.

14. Piao HZ, Choi IY, Park JS, Kim HS, Cheong JH, Son KH, Jeon SJ, Ko KH and Kim WK: Wogonin inhibits microglial cell migration via suppression of nuclear factor-kappa B activity. Int Immunopharmacol 8: 1658-1662, 2008.

15. Lin CM, Chen YH, Ong JR, Ma HP, Shyu KG and Bai KJ: Functional role of wogonin in anti-angiogenesis. Am J Chin Med 40: 415-427, 2012.

16. Chi YS, Lim H, Park H and Kim HP: Effects of wogonin, a plant flavone from Scutellaria radix, on skin inflammation: In vivo regulation of inflammation-associated gene expression. Biochem Pharmacol 66: 1271-1278, 2003.

17. Lin CM, Chang H, Chen YH, Li SY, Wu IH and Chiu JH: Protective role of wogonin against lipopolysaccharide-induced angiogenesis via VEGFR-2, not VEGFR-1. Int Immunopharmacol 6: 1690-1698, 2006.

18. Burke JM: Epithelial phenotype and the RPE: Is the answer blowing in the Wnt? Prog Retin Eye Res 27: 579-595, 2008.

19. Chen S, Xiong J, Zhan Y, Liu W and Wang X: Wogonin inhibits LPS-induced inflammatory responses in rat dorsal root ganglion neurons via inhibiting TLR4-MyD88-TAK1-mediated NF- $\kappa$ B and MAPK signaling pathway. Cell Mol Neurobiol 35: 523-531, 2015.

20. Chen F, Wu R, Zhu Z, Yin W, Xiong M, Sun J, Ni M, Cai G and Zhang $\mathrm{X}$ : Wogonin protects rat dorsal root ganglion neurons against tunicamycin-induced ER stress through the PERK-eIF2 $\alpha$-ATF4 signaling pathway. J Mol Neurosci 55: 995-1005, 2015.

21. Xu S, Zhao X, Zhao Q, Zheng Q, Fang Z, Yang X, Wang H, Liu P and $\mathrm{Xu} \mathrm{H}$ : Wogonin prevents rat dorsal root ganglion neurons death via inhibiting tunicamycin-induced ER stress in vitro. Cell Mol Neurobiol 35: 389-398, 2015.

22. Wang W, Xia T and Yu X: Wogonin suppresses inflammatory response and maintains intestinal barrier function via TLR4-MyD88-TAK1-mediated NF- $\mathrm{B}$ pathway in vitro. Inflamm Res 64: 423-431, 2015.

23. Livak KJ and Schmittgen TD: Analysis of relative gene expression data using real-time quantitative PCR and the 2(-Delta Delta C(T)) Method. Methods 25: 402-408, 2001.

24. Shen W, Gao Y, Lu B, Zhang Q, Hu Y and Chen Y: Negatively regulating TLR4/NF- $\kappa B$ signaling via PPAR $\alpha$ in endotoxin-induced uveitis. Biochim Biophys Acta 1842: 1109-1120, 2014. 
25. Paeng SH, Park WS, Jung WK, Lee DS, Kim GY, Choi YH, Seo SK, Jang WH, Choi JS, Lee YM, et al: YCG063 inhibits Pseudomonas aeruginosa LPS-induced inflammation in human retinal pigment epithelial cells through the TLR2-mediated $\mathrm{AKT} / \mathrm{NF}-\mathrm{\kappa B}$ pathway and ROS-independent pathways. Int J Mol Med 36: 808-816, 2015.

26. Mateos MV, Kamerbeek CB, Giusto NM and Salvador GA: The phospholipase D pathway mediates the inflammatory response of the retinal pigment epithelium. Int J Biochem Cell Biol 55: 119-128, 2014.

27. Breccia $\mathrm{M}$ and Alimena $\mathrm{G}: \mathrm{NF}-\kappa \mathrm{B}$ as a potential therapeutic target in myelodysplastic syndromes and acute myeloid leukemia. Expert Opin Ther Targets 14: 1157-1176, 2010.
28. He X, Wei Z, Zhou E, Chen L, Kou J, Wang J and Yang Z: Baicalein attenuates inflammatory responses by suppressing TLR4 mediated NF- $\kappa \mathrm{B}$ and MAPK signaling pathways in LPS-induced mastitis in mice. Int Immunopharmacol 28: 470-476, 2015.

29. Wardill HR, Van Sebille YZ, Mander KA, Gibson RJ, Logan RM, Bowen JM and Sonis ST: Toll-like receptor 4 signaling: A common biological mechanism of regimen-related toxicities: An emerging hypothesis for neuropathy and gastrointestinal toxicity. Cancer Treat Rev 41: 122-128, 2015 